\title{
Stem Cell-based Tolerance Induction in Transplantation
}

Saami Khalifian', Johanna Grahammer ${ }^{2}$, W.P. Andrew Lee ${ }^{1}$ and Gerald Brandacher ${ }^{1 *}$

${ }^{1}$ Department of Plastic and Reconstructive Surgery, Johns Hopkins University School of Medicine, Baltimore, MD, USA

${ }^{2}$ Center of Operative Medicine, Department of Visceral, Transplant and Thoracic Surgery, Innsbruck Medical University, Innsbruck, Austria

\begin{abstract}
The use of stem cell-based protocols in transplantation has rapidly achieved many long-sought goals, including the induction of donor-specific tolerance and as an effective immunomodulatory therapy against acute cellular rejection and graft-versus-host disease. Recent advances in the fields of transplant immunology and regenerative medicine have significantly improved outcomes after solid organ and vascularized composite allotransplantation, as evidenced by data from preclinical, translational, and clinical trials. Specifically, stem cell therapies have been shown to diminish effector $\mathrm{T}$ cell responses, expand regulatory $\mathrm{T}$ cell populations, decrease the incidence and severity of rejection, improve nerve regeneration, and facilitate the induction of mixed hematopoietic chimerism. This review summarizes the latest developments in the use of mesenchymal and hematopoietic stem cell-based therapies in advancing the field of transplantation by eliminating the need for systemic life-long immunosuppression.
\end{abstract}

Keywords: Stem cell; Tolerance; Transplant; Solid organ; Vascularized composite; Immunosuppression; Mesenchymal; Hematopoietic; Chimerism; MSC; HSC

Abbreviations: SOT: Solid Organ Transplantation; VCA: Vascularized Composite Allotransplantation; MSCs: Mesenchymal Stem Cells; HSCs: Hematopoietic Stem Cells; HSCT: Hematopoietic Stem Cell Transplantation; ASCs: Adipose-derived Stromal Cells; BMSCs: Bone Marrow Derived Stromal Cells; BM: Bone Marrow; GVHD: Graft-versus-host Disease; Tregs: Regulatory T cells; Mregs: Regulatory Macrophages; tolDCs: Tolerogenic Dendritic Cells

\section{Introduction}

Solid organ transplantation (SOT) is one of the most remarkable therapeutic advances in medicine of the last century. Although surgical techniques that made SOT feasible were in place by the turn of the $20^{\text {th }}$ century, early outcomes after organ transplantation were poor until the first successful living-related kidney transplantation performed in 1954 by Dr. Joseph E Murray [1]. Nearly 60 years later, this procedure has become the standard of care for the treatment of patients with endstage renal disease, and has proven to be life-saving and cost-effective.

The wealth of knowledge gained from the field of SOT, as well as the development of powerful immunosuppressive drugs in the 1980's, not only led to continuously increased success rates for kidney, liver, pancreas, heart, lung, intestinal, or even multivisceral transplants, but also paved the way for vascularized composite allotransplantation (VCA) to become a clinical reality [2,3]. Since the first successful hand transplantation in 1998, [4] a variety of other tissues and body parts have been transplanted including face, larynx, trachea, abdominal wall, knee, and femur, with highly encouraging immunological and functional outcomes [5].

However, the potent immunosuppressive drugs that make SOT and VCA possible by preventing acute cellular rejection also expose transplant recipients to considerable unwanted side effects including opportunistic infections, metabolic disturbances, or even malignancy [6]. Indeed, the risk of these complications precludes the widespread application of VCA in becoming the standard of care for patients with complex, disfiguring, and disabling injuries that are not amenable to conventional reconstruction. This is because unlike SOT, which is a lifesaving procedure, VCA is a life-changing procedure typically performed in young and otherwise healthy patients; thus, the acceptable risk-to- benefit profile is divergent between these two fields of transplantation.

Recent progress in cell and stem cell biology has shown significant potential for filling the critically unmet need of immunosuppression minimization and/or withdrawal after transplantation, which would improve long-term outcomes after SOT and widen the indications for VCA. Various stem cell-based approaches have been utilized in an attempt to achieve donor-specific tolerance-a goal that would overcome the shortcomings of systemic, life-long, high-dose, multidrug immunosuppression and could possibly allow for indefinite graft survival $[7,8]$. Herein we will review the recent progress in the use of stem cell-based therapies in promoting transplant tolerance and immunosuppression minimization in SOT and VCA. We will discuss the critical balance of effector and regulatory cells that modulate tolerance induction, review the role of mesenchymal stem cells (MSCs) in combating acute cellular rejection and GVHD, and highlight the use of hematopoietic stem cells (HSCs) in achieving tolerance to allografts via induction of mixed hematopoietic chimerism.

\section{Tolerance Induction: A Balancing Act}

Transplantation of foreign tissues, particularly when it involves a major histocompatibility complex (MHC)-incompatible graft, triggers the activation of effector $\mathrm{T}$ cells that contribute to allograft destruction and dysfunction, as well as the proliferation of regulatory $\mathrm{T}$ cells (Tregs) that aid in graft protection and survival. Indeed, it is the delicate balance between these two $\mathrm{T}$ cell subsets that determines the allograft's fate, and the relative proportion of these $\mathrm{T}$ cell subsets is modulated in part by the degree of MHC-mismatch [7]. Whereas there are established allocation

*Corresponding author: Gerald Brandacher MD, Scientific Director Reconstructive Transplantation Program, Department of Plastic and Reconstructive Surgery, Johns Hopkins University School of Medicine, Ross Research Building, Room 749D, 720 Rutland Avenue, Baltimore, MD 21205, USA, Tel: (443) 2876679; Fax: (410)614-1296; E-mail: brandacher@jhmi.edu

Received November 06, 2013; Accepted December 10, 2013; Published December 12, 2013

Citation: Khalifian S, Grahammer J, Andrew Lee WP, Brandacher G (2013) Stem Cell-based Tolerance Induction in Transplantation. J Stem Cell Res Ther S6: 003. doi:10.4172/2157-7633.S6-003

Copyright: (c) 2013 Khalifian S, et al. This is an open-access article distributed under the terms of the Creative Commons Attribution License, which permits unrestricted use, distribution, and reproduction in any medium, provided the original author and source are credited. 
criteria such as blood group and MHC-matching for SOT, the retrieval of VCA has historically not been matched for MHC as the availability of donors with appropriate skin color, size, sex, and age match has been far more limiting for the transplantation of visible grafts such as hand or face [9]. Therefore, solid organ transplant recipients, and particularly VCA recipients, are at risk for activation of effector adaptive immune responses that puts their allograft in jeopardy from the moment the graft is transplanted.

Considerable research has been invested in skewing the balance towards Tregs with a concomitant decrease in $\mathrm{T}$ effectors, either by anergy induction or depletion of alloreactive $\mathrm{T}$ effector cells. Tregs are amongst the most prominent class of immunomodulatory cells and can develop naturally in the thymus or can be induced in response to antigen-stimulation under tolerogenic conditions in the periphery $[10,11]$. Regardless of the source, Tregs have been shown to control immune responses to foreign antigens and likely contribute to tolerance induction and maintenance in transplanted tissues, as evidenced by a multitude of animal studies and supporting findings from tolerant organ recipients [12-14]. Tregs also effectively control GVHD as demonstrated by a study of haploidentical HSC transplantation in subjects that received initial pretreatment without any other conventional immunosuppression, followed by an infusion of Tregs and a subsequent infusion of effector $\mathrm{T}$ cells at a later time-a scenario that would make GVHD very likely [15]. These subjects did surprisingly well with satisfactory immune reconstitution, rare occurrences of acute GVHD, and no signs of chronic GVHD at one-year follow up. However, the translation of Treg protocols from preventive GVHD studies to SOT and VCA is expected to require significantly higher numbers of Tregs in order to be effective [16].

Attempts to culture Tregs to expand and favorably skew the $\mathrm{T}$ effector:Treg balance have not been overwhelmingly successful, as Tregs are sparse in the peripheral circulation, which makes isolation of sufficient numbers difficult. Notably, contamination during isolation and plasticity of Tregs in culture further impedes their widespread clinical applicability. Thus, alternative strategies have been sought to realize the potential for Tregs with definitive antigen-specificity to suppress anti-donor reactivity while sparing other immune responses.

One promising strategy to achieve this goal is the use of MSCs, a potent immunomodulatory cell population that exerts its immunoregulatory effects on both the innate and adaptive immune system $[17,18]$. Studies have demonstrated that MSCs selectively induce the proliferation of Tregs with strong suppressive capacity, favorably skewing the proportion of Tregs and $\mathrm{T}$ effectors towards a regulatory phenotype $[19,20]$. There is also evidence that MSCs participate in the suppression of Th1, Th2, and Th17 responses, with a concomitant suppression of $\mathrm{T}$ effector and $\mathrm{T}$ memory cells $[21,22]$. Furthermore, studies have shown that MSCs inhibit hematopoietic cells after in vivo administration, constitutively secrete anti-inflammatory factors, and inhibit the proliferation of PBMC and their production of inflammatory cytokines $[19,23,24]$. Thus, the potent immunosuppressive capacity of MSCs underlines their importance as cellular immune therapy in SOT and VCA.

\section{The Role of MSCs in the Generation of Regulatory Cell Types}

MSCs possess unique immunomodulatory characteristics and are present in most tissues including adipose tissue, bone marrow, heart, Wharton's jelly, umbilical cord, and peripheral blood [25]. They are characterized by their immunophenotype, fibroblast-like morphology, and multilineage differentiation capacity, which include adipocytes, chondrocytes, myocytes, neuronal precursor cells, Schwann cells, and osteoblasts. Characteristics of MSCs have been described in detail elsewhere [26-28].

MSCs have a wide range of immunological functions including tissue regeneration and protection from ischemia-related damage, and exert their immunoregulatory effects on a variety of cell types through the release of soluble factors and cell-cell contact $[29,30]$. The optimal source of MSCs used for tissue engineering and cell therapy has been a matter of debate. Various groups have pointed out key differences between two primary subtypes of MSCs: adiposederived stromal cells (ASCs) and bone marrow-derived stromal cells (BMSCs) [25]. In summary, ASCs appear to have superior proliferative capacity, increased genetic stability, more potent immunosuppressive and immunomodulatory capabilities in vitro and in vivo, and adipose tissue provides a richer source of stem cells with higher yield and easier procurement than bone marrow, which translates to a significantly shortened time from cell harvest to infusion when compared with BMSCs.

There is growing in vitro and in vivo evidence demonstrating the ability of MSC-based therapies to induce the generation of regulatory cell types, which highlights their potential for tolerance induction. MSCs have been shown to directly induce differentiation of CD4+ $\mathrm{T}$ cells to Tregs, induce a Treg phenotype in naive and memory $\mathrm{T}$ cells, and expanded Tregs are capable of suppressing antigen-specific proliferative responses in vitro and ex vivo [20,31,32]. Various mediators have been implicated in the generation of Treg by MSCs, including IFN- $\gamma$, prostaglandin E2, and indoleamine 2,3-dioxygenase (IDO), amongst others [33]. Furthermore, MSCs have been shown to reprogram Th17 cells into Tregs and inhibit the activation of cytotoxic lymphocytes [34]. Multiple experimental models of inflammatory and autoimmune diseases have corroborated these in vitro findings. For example, in animal models of colitis, diabetes, myasthenia gravis, and systemic lupus erythematous, groups have consistently reported that MSC infusion was associated with an increased proportion of Tregs and diminished Th1 and Th17 development [35-38]. Clearly, the generation of Tregs, modulation of immune responses, and inhibition of inflammatory states by MSCs would be of benefit to transplantation, which has led to an intense investigation of their effects in SOT and VCA as will be described later.

MSCs have also been shown to promote the generation of tolerogenic dendritic cells (tolDCs), a unique regulatory cell subtype that contributes to the production of Tregs with a diminished capacity to stimulate $\mathrm{T}$ cell proliferation [39-41]. The mechanism of action of tolDCs is still unclear. The commonly accepted explanation contends that a direct interaction of $e x$ vivo generated tolDCs renders $\mathrm{T}$ effector cells anergic and apoptotic; however, recent evidence suggests that infused tolDCs have a short half-life after infusion and are taken up by recipient antigen presenting cells (APCs). These experiments suggest that the mechanism of action of tolDC is actually mediated by recipient APCs and not directly by the tolDCs [42,43]. Multiple clinical trials investigating the use of tolDC therapy in rheumatoid arthritis patients are currently underway, as well as ongoing trials investigating the outcomes of tolDCs applied in combination with various immunosuppressive drugs (Tacrolimus, MMF, etc.), which has significant implications for the field of transplantation [41,44]. Data regarding the use of tolDC has been positive overall and forthcoming studies on the application of this regulatory cell type in SOT and VCA are eagerly anticipated. 
The modulation of immune cells by MSCs extends to macrophages as well, which can be polarized by MSCs toward an anti-inflammatory phenotype with capacity to expand Treg populations [45]. This increasingly recognized cell population is sometimes referred to as regulatory macrophages (Mregs). Mregs are fully matured macrophages with a distinct phenotype and well-characterized expression of surface markers [46]. Specifically, MSCs promoted the generation of IL-10 secreting Mregs from the monocyte fraction of PBMCs in vitro by upregulating the expression of IDO [47]. Francois et al. [46] demonstrated that Mregs are able to suppress $\mathrm{T}$ cell proliferation in vitro, induce the expansion of Tregs, and amplified the immunosuppressive effect generated by MSCs. Similar results have been generated in pilot studies of kidney transplantation, where the perioperative infusion of donor-derived Mregs into two kidney transplant recipients facilitated the weaning of conventional immunosuppression to low-dose tacrolimus monotherapy after several weeks with no episodes of acute rejection reported thus far. Imaging studies in these patients revealed that the infused Mregs migrated to the bone marrow, liver, and spleen and were detectable in these sites at least 30 hours after infusion. These studies confirm that MSCs likely play a role in inducing regulatory macrophages in humans with capacity to improve transplantation outcomes.

The summation of this in vitro and in vivo data together with early results from clinical trials clearly elucidate the potent capacity of MSCs to effectively modulate immune responses in inflammatory, autoimmune, and transplantation settings. The key effect in this immune modulation by MSCs appears to be the generation of Tregs and other regulatory cell types, and a concomitant diminution of $\mathrm{T}$ effector cells.

\section{The Use of MSCs in Solid Organ and Reconstructive Transplantation}

The wealth of in vitro and in vivo data confirm that MSCs favorably modulate immune responses that drive the rejection process and therefore have the potential to positively affect outcomes in both SOT and VCA. Certainly, the similarities between these sister fields facilitates rapid translation of immunological findings between them. Elucidation of the mechanisms and players responsible for acute cellular rejection is exceedingly similar, and the collection of immunsuppressive drugs used between these fields is essentially the same. In fact, the amount of immunosuppression required in VCA is only slightly higher than what is used in kidney transplantation and comparable to what is given in pancreas transplantation [48]. In this section, we highlight important differences between the fields of SOT and VCA, and summarize pertinent experimental and clinical findings regarding the use of MSCs in transplantation.

Many of the challenges faced by SOT remain true for VCA, such as the risk of graft-versus-host disease (GVHD) or the consequences of life-long, systemic immunosuppression. One unique difference in VCA is the requirement for nerve regeneration over long distances to regain full motor and sensory function. In addition to immunological and aesthetic outcomes, functional recovery is a key determinant of overall success in VCA and this critically depends on the quality and pace of nerve regeneration. In this regard, MSCs have shown considerable promise in animal models of peripheral nerve and spinal cord injury, where the use of MSCs improved electrophysiological outcomes after peripheral nerve injury, accelerated spinal fusion in a rat model of lumbar compression fracture, and significantly improved hind limb function and nerve conduction in a canine model of spinal cord injury [49-51]. Furthermore, MSCs seeded into a fibrin conduit in a rat sciatic nerve transection model were shown to significantly increase the distance of axonal regeneration [52]. Thus, the enhancement of nerve regeneration across long distances by MSCs may overcome some of the challenges faced by VCA that currently limit its expansion to arm and lower extremity transplantation.

Yet, rejection remains the most important hurdle impeding the success and widespread clinical application of all types of transplantation. Although the mechanisms of rejection are likely the same between SOT and VCA, the diversity of tissues contained in a vascularized composite allograft inherently trigger different rates and intensities of rejection that target different tissues [53]. While the skin is the most immunogenic portion of a VCA allograft, and therefore the principal target of rejection, it also provides a unique opportunity for the monitoring, early diagnosis, prevention, and treatment of rejection. This opportunity for early intervention and treatment of acute skin rejection may explain the lack of chronic rejection episodes in VCA thus far [5]. Furthermore, due to its external location, there is the distinct possibility of therapies that could be applied directly to the skin. Currently, topical immunosuppressive agents have had limited success in the clinical arena for VCA, but the novel immunomodulatory properties of MSCs may be capable of quelling the rejection response in the skin either via topical or local application. Nevertheless, current data on the use of MSCs in large animal models of VCA is limited to systemic infusions, albeit with highly encouraging results. In a swine hind limb and hemi-facial model of VCA, multiple infusions of allogeneic MSCs with short-term conventional immunosuppression led to indefinite graft survival with increased levels of Tregs in the allograft and the periphery [54,55]. Indeed, if the rejection response to the skin could be adequately controlled, the withdrawal of immunosuppression in VCA recipients would be much more likely and this could potentially broaden indications for reconstructive transplantation to include tumor resection and congenital malformations.

The successful application of MSCs in transplantation extends beyond modulation of acute rejection, as these cells have also effectively prevented acute GVHD in both preclinical and clinical trials [5661]. Transplantation of allogeneic ASCs efficiently treated GVHD in seven out of nine recipients, including in severe steroid-refractory cases, after major ABO-incompatible HSC transplantation, as salvage therapy for severe hepatic GVHD, and rescue treatment for repetitive rejection of bone marrow transplants [59-62]. In fact, in the case of major ABO-incompatible HSC transplantation, the infusion of MSCs led to resolution of refractory pure red cell aplasia. The mechanism responsible for these improved outcomes remains to be fully elucidated; however, it is likely due in part to a shift away from a pro-inflammatory cytokine milieu towards an anti-inflammatory micro-environment [56]. Furthermore, due to the low immunogenicity of MSCs (they lack expression of HLA-DR) and their capacity to suppress alloreactive T cell proliferation, these stem cells can be transplanted across MHC barriers without inciting an immune response. This has significant implications for transplantation, as infusion of allogeneic MSCs together with vascularized composite allografts or donor solid organs may reduce or eliminate the risk of GVHD, and potentially enhance engraftment [30]. There is already considerable evidence supporting this conclusion. For example, Fang et al. [59] reported their findings that infusion of ASCs led to complete resolution of acute GVHD in over $80 \%$ of their HSC transplant recipients with a median follow-up of 40 months. Currently, there is a paucity of results from clinical trials investigating the use of MSCs in preventing GVHD in reconstructive transplantation; however, swine models of VCA have shown that the use of MSCs with conventional immunosuppression prolonged allograft survival to more 
than 200 days without signs of GVHD or rejection in donor skin/muscle biopsies [63]. This recent evidence highlights the immunomodulatory potential of MSCs in the treatment and prophylaxis of GVHD.

Human studies of MSC-based therapy for facilitation of hematopoietic stem cell (HSC) engraftment in SOT and bone marrow (BM) transplantation have also been relatively successful $[17,33,64]$. Clinical trials have shown rapid hematopoietic recovery with minimal side effects from allogeneic MSC infusion [24,65]. Notably, while MSCs may promote engraftment of transplanted HSCs, the donor MSCs themselves undergo negligible engraftment into host BM [66]. MSCs likely facilitate such engraftment by supporting the cells within the HSC niche and by decreasing the allostimulatory capacity of peripheral blood stem cells $[67,68]$.

The sum of these findings indicate that MSCs are a promising immunomodulatory strategy to prevent rejection, adequately treat and inhibit GVHD, facilitate BM and HSC engraftment, and may potentially augment tolerance induction in both SOT and VCA. Further studies will be required to more clearly define the mechanisms through which MSCs exert their effects, and randomized controlled trials will be necessary to quantify the benefits of MSC-based therapy and compare it to both standard therapy as well as other promising strategies, such as HSC-based protocols.

\section{HSCs Augment Tolerance Induction via Transient or Permanent Chimerism}

Hematopoietic stem cell transplantation (HSCT) has proven to be a robust approach for the induction of transplant tolerance, with over two decades of research in humans and multiple SOT recipients weaned off immunosuppression with no evidence of chronic rejection [69]. Early studies utilizing HSCT combined this approach with recipient myeloablative treatment (irradiation and/or chemotherapy) followed by infusion of hematopoietic stem and progenitor cells from BM [70]. Due to the highly immunogenic nature of BM, conditioning regimens such as total body irradiation were deemed necessary to prevent a strong alloimmune response and to create "physiological space" to permit HSC engraftment in the recipient's BM niche [71,72]. However, the high doses of irradiation/chemotherapy carried significant toxicity including a high risk of GVHD, which limited the use of such protocols primarily to pediatric patients with hematological malignancies. Thus, considerable efforts were invested into the development of nonmyeloabaltive conditioning regimens, which had reduced intensity and substantially less systemic toxicity. Over time, myeloablative therapies such as total body irradiation were replaced by myelosuppressive drugs (e.g. T-cell depleting antibodies), and shortly thereafter by selective thymic irradiation to reduce intensity $[73,74]$. Such protocols are now well established in preclinical and translational animal models, even across major MHC barriers.

Notably, the mechanism of HSC-mediated tolerance to allografts likely occurs through induction of mixed hematopoietic chimerism. Mixed chimerism is unlike full chimerism, which is achieved after myeloablative conditioning regimens cause failure of host hematopoiesis with subsequent total reconstitution by donor HSCs (a state associated with reduced immunocompetence against infection and significantly increased risk of GVHD) [69]. Rather, mixed chimerism is a state where hematopoietic cells of donor and host origin coexist while maintaining normal immunocompetence, typically achieved through non-myeloablative regimens and mechanisms of central and peripheral deletion of alloreactive $\mathrm{T}$ cells $[75,76]$. Recent evidence suggests that central chimerism requires donor dendritic cells in the thymus to continuously display donor antigens as "self" to naïve thymocytes facilitating negative selection of alloreactive T cells $[77,78]$. Many preclinical, translational, and clinical trials have shown a clear correlation between macrochimerism and stable allograft acceptance $[79,80]$. Here we will review the progress of HSCT in the induction of tolerance to solid organ and vascularized composite allografts.

There is a plethora of research suggesting that mixed chimerism can effectively induce tolerance to transplanted organs. Murine studies in the 1980's demonstrated that preconditioning of mice with lethal irradiation followed by reconstitution with a BM mixture from both recipient and donor strains successfully induced mixed chimerism and achieved long-term tolerance to allogeneic donor tissues [81]. However, such an approach carried significant toxicity, as described earlier, and therefore this approach was not suitable for clinical SOT or VCA. Therefore, ensuing studies began to utilize the novel nonmyeloablative conditioning regimens of the time, which facilitated donor BM engraftment with reduced toxicity and the capacity to carry out BM transplantation across MHC barriers [75,82].

It soon became clear that the use of HSCT could also be used to induce long-term tolerance to renal allografts from the same donor in large animal models, even across MHC barriers [83-85]. There are conflicting reports regarding the stability of mixed chimerism in these studies; nevertheless, long-term tolerance to renal allografts was achieved, even when mixed chimerism was only transient. Notably, mixed chimerism is the only approach to have successfully induced tolerance to solid organ transplants in fully MHC-mismatched nonhuman primates [86]. In this study, HSCT facilitated kidney allograft acceptance, and subsequently skin grafts were accepted from the same donor, while third-party skin grafts were rejected [87].

These large animal protocols were subsequently adapted and successfully applied to clinical trials with highly encouraging results. The first studies entailed the use of combined HLA-matched BM and renal transplantation in patients with renal failure due to multiple myeloma [73]. This was followed by clinical trials using HLA-matched renal allografts and HSCT in patients without malignancy, and finally renal transplantation with concurrent HSCT in HLA-mismatched recipients [74,88-90]. Remarkably, tolerance induction was successfully achieved in nearly all of these patients, with ongoing reports of prolonged immunosuppression-free survival, ranging between 2-13 years, without evidence of rejection and infrequent occurrences of GVHD.

Again, the mechanism responsible for tolerance induction to these renal allografts remains unclear. Some studies have suggested that host Tregs that survive the conditioning regimen may contribute to suppressing allograft rejection; others contend that the kidney allograft itself may possess some tolerogenic property effectively inducing or maintaining tolerance [14,91]. Although the mechanism responsible for allograft tolerance induction via mixed chimerism remains to be fully elucidated, it appears that this approach can successfully induce long-term, immunosuppression-free survival to solid organ allografts across MHC-barriers-a long sought goal for the field of transplant immunology.

The success of HSCT in inducing tolerance to renal allografts led to its application in the field of VCA. Although long-term outcomes investigating the use of HSCT and mixed chimerism in translational animal models of VCA is limited, the results are certainly encouraging. One of the earliest chimerism-based protocols in VCA, found that tolerance could be induced in a rat model with sufficient pretreatment, 
and that chimerism levels above $20 \%$ led to indefinite graft survival [92]. In another study, donor HSC infusion with a short course of conventional immunosuppression, also successfully induced tolerance in a rat hind limb model without any pretreatment, which was a major advancement since cadaveric allograft donation typically precludes pretreatment of the recipient [93].

Translational studies in swine also investigated the role of donor bone marrow in inducing tolerance via chimerism. However, early studies using the heterotopic hind limb model in swine did not use donor BM infusion, since the allograft already contained a vascularized bone marrow component that was rich in donor HSCs [94]. Although transient mixed chimerism was identified early on, chimerism was lost after two months [95]. Regardless, these animals remained tolerant to their graft indefinitely.

Notably, these early studies in swine did not contain a skin paddle, which limits its translation to human VCA, which typically does contain the highly immunogenic skin component. Subsequently, a myocutaneous VCA transplant was performed in an MHC-matched canine model using nonmyeloablative conditioning and HSCT to achieve persistent mixed chimerism and tolerance induction [96]. In this study, all five recipients successfully accepted their allograft for over one year, with evidence of increased levels of Tregs in skin, muscle, and graft-draining lymph node. However, the clinical relevance of such a model in VCA is low, since HLA-matching would be unlikely in the setting of reconstructive transplantation. Thus, heterotopic hind limb transplantation was performed in a fully mismatched swine model after nonmyeloablative preconditioning (without radiation) and HSCT plus 30 days of cyclosporine A post-transplant [97]. Although these animals developed tolerance to the musculoskeletal components of the allograft, the skin rejected by day 60 with some recipients experiencing cutaneous GVHD.

Recent studies suggest that tolerance to the skin requires donor HSC engraftment to facilitate negative selection of skin-antigenspecific alloreactive $\mathrm{T}$ cells centrally, whereas $\mathrm{T}$ cells specific to other components of the allograft (e.g. muscle) may be controlled by Tregs in the periphery even if they escape deletion in the thymus [69]. Indeed, Horner et al demonstrated that when HSC engraftment is successful, persistent chimerism is seen in multiple tissues, with induction of tolerance to vascularized skin (and solid organ transplants using the same protocol) across major MHC-barriers in swine. These results suggest that the induction of donor-specific tolerance in VCA is possible. Further studies are necessary to elucidate the optimal preconditioning regimen, route, dosage, and composition of HSCT in translational models, in addition to well-designed, multi-center clinical trials evaluating the efficacy of such approaches in VCA recipients.

\section{Conclusion}

Stem cell-based protocols have helped realize many long-sought goals in transplantation. Substantial progress has been made over the years with the use of stem cells, including a significant decrease in the rate and severity of rejection, modulation of effector and regulatory cell types, treatment and prophylaxis against GVHD, improved and accelerated nerve regeneration across long distances, and the facilitation of immunosuppression withdrawal and tolerance induction. Although further research is required to fully delineate the mechanisms by which MSCs and HSCs exert these effects, there is no doubt that the use of stem cells in the field of transplantation has positively affected outcomes and helped bring us one step closer to our ultimate goal of long-term tolerance induction. Indeed, donor-specific tolerance would obviate the need for systemic, life-long immunosuppression that carries significant side effects and currently limits the indications for VCA. As the field of regenerative medicine and transplantation continue to merge their efforts, the application of stem cell-based protocols will likely continue to improve outcomes and enable wider clinical application of these lifesaving and life-changing procedures.

\section{Conflicts of Interest}

The authors have no relevant financial disclosures or conflicts of interest to report.

\section{References}

1. Guild WR, Harrison JH, Merrill JP, Murray J (1955) Successful homotransplantation of the kidney in an identical twin. Trans Am Clin Climatol Assoc 67: 167-173.

2. Kino T, Hatanaka H, Miyata S, Inamura N, Nishiyama M, et al. (1987) FK-506, a novel immunosuppressant isolated from a Streptomyces. II. Immunosuppressive effect of FK-506 in vitro. J Antibiot (Tokyo) 40: 1256-1265.

3. Murray JE (1971) Organ transplantation (skin, kidney, heart) and the plastic surgeon. Plast Reconstr Surg 47: 425-431.

4. Dubernard JM, Owen E, Herzberg G, Lanzetta M, Martin X, et al. (1999) Human hand allograft: report on first 6 months. Lancet 353: 1315-1320.

5. Petruzzo P, Lanzetta M, Dubernard JM, Landin L, Cavadas P, et al. (2010) The International Registry on Hand and Composite Tissue Transplantation. Transplantation 90: 1590-1594.

6. Schneeberger S, Khalifian S, Brandacher G. Immunosuppression and monitoring of rejection in hand transplantation. Techniques in hand \& upper extremity surgery, 17(4), 208-214 (2013).

7. Sayegh MH, Remuzzi G (2007) Clinical update: immunosuppression minimisation. Lancet 369: 1676-1678.

8. Casiraghi F, Perico N, Remuzzi G (2013) Mesenchymal stromal cells to promote solid organ transplantation tolerance. Curr Opin Organ Transplant 18: 51-58.

9. Weissenbacher A, Hautz T, Pratschke J, Schneeberger S (2013) Vascularized composite allografts and solid organ transplants: similarities and differences. Curr Opin Organ Transplant.

10. Curotto de Lafaille MA, Lafaille JJ (2009) Natural and adaptive foxp3+ regulatory T cells: more of the same or a division of labor? Immunity 30: 626-635.

11. Sakaguchi S (2005) Naturally arising Foxp3-expressing CD25+CD4+ regulatory T cells in immunological tolerance to self and non-self. Nature immunology 6 : 345-352.

12. Wood KJ, Sakaguchi S (2003) Regulatory T cells in transplantation tolerance. Nat Rev Immunol 3: 199-210.

13. Li XC, Turka LA (2010) An update on regulatory T cells in transplant tolerance and rejection. Nat Rev Nephrol 6: 577-583.

14. Andreola G, Chittenden M, Shaffer J, Cosimi AB, Kawai T, et al. (2011) Mechanisms of donor-specific tolerance in recipients of haploidentical combined bone marrow/kidney transplantation. Am J Transplant 11: 1236-1247.

15. Di lanni M, Falzetti F, Carotti A, Terenzi A, Castellino F, et al. (2011) Tregs prevent GVHD and promote immune reconstitution in HLA-haploidentical transplantation. Blood 117: 3921-3928.

16. Schliesser U, Streitz M, Sawitzki B (2012) Tregs: application for solid-organ transplantation. Curr Opin Organ Transplant 17: 34-41.

17. Griffin MD, Ritter T, Mahon BP (2010) Immunological aspects of allogeneic mesenchymal stem cell therapies. Human gene therapy 21: 1641-1655.

18. Le Blanc K, Mougiakakos D (2012) Multipotent mesenchymal stromal cells and the innate immune system. Nat Rev Immunol 12: 383-396.

19. Aggarwal S, Pittenger MF (2005) Human mesenchymal stem cells modulate allogeneic immune cell responses. Blood 105: 1815-1822.

20. Di lanni M, Del Papa B, De loanni M, Moretti L, Bonifacio E, et al. (2008) Mesenchymal cells recruit and regulate T regulatory cells. Exp Hematol 36: 309-318. 
Citation: Khalifian S, Grahammer J, Andrew Lee WP, Brandacher G (2013) Stem Cell-based Tolerance Induction in Transplantation. J Stem Cell Res Ther S6: 003. doi:10.4172/2157-7633.S6-003

Page 6 of 7

21. Duffy MM, Ritter T, Ceredig R, Griffin MD (2011) Mesenchymal stem cell effects on T-cell effector pathways. Stem Cell Res Ther 2: 34.

22. Krampera M, Glennie S, Dyson J, Scott D, Laylor R, et al. (2003) Bone marrow mesenchymal stem cells inhibit the response of naive and memory antigenspecific T cells to their cognate peptide. Blood 101: 3722-3729.

23. Krampera M, Cosmi L, Angeli R, Pasini A, Liotta F, et al. (2006) Role for interferon-gamma in the immunomodulatory activity of human bone marrow mesenchymal stem cells. Stem Cells 24: 386-398.

24. Lazarus HM, Koc ON, Devine SM, Curtin P, Maziarz RT, et al. (2005) Cotransplantation of HLA-identical sibling culture-expanded mesenchymal stem cells and hematopoietic stem cells in hematologic malignancy patients. Biol Blood Marrow Transplant 11: 389-398.

25. Leto Barone AA, Khalifian S, Lee WP, Brandacher G (2013) Immunomodulatory Effects of Adipose-Derived Stem Cells: Fact or Fiction? BioMed research international 2013: 383685 .

26. Pittenger MF, Mackay AM, Beck SC, Jaiswal RK, Douglas R, et al. (1999) Multilineage potential of adult human mesenchymal stem cells. Science 284 : 143-147

27. Jiang Y, Jahagirdar BN, Reinhardt RL, Schwartz RE, Keene CD, et al. (2002) Pluripotency of mesenchymal stem cells derived from adult marrow. Nature 418: 41-49.

28. Crop M, Baan C, Weimar W, Hoogduijn M (2009) Potential of mesenchymal stem cells as immune therapy in solid-organ transplantation. Transpl Int 22 : 365-376

29. Puissant B, Barreau C, Bourin P, Clavel C, Corre J, et al. (2005) Immunomodulatory effect of human adipose tissue-derived adult stem cells: comparison with bone marrow mesenchymal stem cells. $\mathrm{Br} \mathrm{J}$ Haematol 129: 118-129

30. Yoo KH, Jang IK, Lee MW, Kim HE, Yang MS, et al. (2009) Comparison of immunomodulatory properties of mesenchymal stem cells derived from adult human tissues. Cell Immunol 259: 150-156.

31. English K, Ryan JM, Tobin L, Murphy MJ, Barry FP, et al. (2009) Cell contact, prostaglandin $\mathrm{E}(2)$ and transforming growth factor beta 1 play non-redundant roles in human mesenchymal stem cell induction of CD4+CD25(High) forkhead box P3+ regulatory T cells. Clin Exp Immunol 156: 149-160

32. Prevosto C, Zancolli M, Canevali P, Zocchi MR, Poggi A (2007) Generation of CD4+ or CD8+ regulatory T cells upon mesenchymal stem cell-lymphocyte interaction. Haematologica 92: 881-888.

33. Singer NG, Caplan Al (2011) Mesenchymal stem cells: mechanisms of inflammation. Annu Rev Pathol 6: 457-478.

34. 3Ghannam S, Pene J, Torcy-Moquet G, Jorgensen C, Yssel H (2010) Mesenchymal stem cells inhibit human Th17 cell differentiation and function and induce a T regulatory cell phenotype. J Immunol 185: 302-312.

35. Bassi EJ, Moraes-Vieira PM, Moreira-Sa CS, Almeida DC, Vieira LM, et al. (2012) Immune regulatory properties of allogeneic adipose-derived mesenchymal stem cells in the treatment of experimental autoimmune diabetes. Diabetes 61: 2534-2545.

36. Gonzalez MA, Gonzalez-Rey E, Rico L, Buscher D, Delgado M (2009) Adiposederived mesenchymal stem cells alleviate experimental colitis by inhibiting inflammatory and autoimmune responses. Gastroenterology 136: 978-989.

37. Kong QF, Sun B, Bai SS, Zhai DX, Wang GY, et al. (2009) Administration of bone marrow stromal cells ameliorates experimental autoimmune myasthenia gravis by altering the balance of Th1/Th2/Th17/Treg cell subsets through the secretion of TGF-beta. J Neuroimmunol 207: 83-91.

38. Sun L, Akiyama K, Zhang H, Yamaza T, Hou Y, et al. (2009) Mesenchymal stem cell transplantation reverses multiorgan dysfunction in systemic lupus erythematosus mice and humans. Stem Cells 27: 1421-1432.

39. Zhang B, Liu R, Shi D, Liu X, Chen Y, et al. (2009) Mesenchymal stem cells induce mature dendritic cells into a novel Jagged-2-dependent regulatory dendritic cell population. Blood 113: 46-57.

40. Zhao ZG, Xu W, Sun L, You Y, Li F, et al. (2012) Immunomodulatory function of regulatory dendritic cells induced by mesenchymal stem cells. Immunol Invest 41: 183-198.

41. Moreau A, Varey E, Beriou G, Hill M, Bouchet-Delbos L, et al. (2012) Tolerogenic dendritic cells and negative vaccination in transplantation: from rodents to clinical trials. Front Immunol 3: 218

42. Divito SJ, Wang Z, Shufesky WJ, Liu Q, Tkacheva OA, et al. (2010) Endogenous dendritic cells mediate the effects of intravenously injected therapeutic immunosuppressive dendritic cells in transplantation. Blood 116: 2694-2705.

43. Wang Z, Divito SJ, Shufesky WJ, Sumpter T, Wang H, et al. (2012) Dendritic cell therapies in transplantation revisited: deletion of recipient $D C s$ deters the effect of therapeutic DCs. Am J Transplant 12: 1398-1408.

44. Giannoukakis N, Phillips B, Finegold D, Harnaha J, Trucco M (2011) Phase I (safety) study of autologous tolerogenic dendritic cells in type 1 diabetic patients. Diabetes care 34: 2026-2032.

45. Ylostalo JH, Bartosh TJ, Coble K, Prockop DJ (2012) Human mesenchymal stem/stromal cells cultured as spheroids are self-activated to produce prostaglandin E2 that directs stimulated macrophages into an anti-inflammatory phenotype. Stem Cells 30: 2283-2296.

46. Hutchinson JA, Riquelme P, Sawitzki B, Tomiuk S, Miqueu P, et al. (2011) Cutting Edge: Immunological consequences and trafficking of human regulatory macrophages administered to renal transplant recipients. J Immunol 187: 2072-2078.

47. Francois M, Romieu-Mourez R, Li M, Galipeau J (2012) Human MSC suppression correlates with cytokine induction of indoleamine 2,3-dioxygenase and bystander M2 macrophage differentiation. Mol Ther 20: 187-195.

48. Hautz T, Brandacher G, Zelger B, Gorantla VS, Lee AW, et al. (2010) Immunologic aspects and rejection in solid organ versus reconstructive transplantation. Transplant Proc 42: 3347-3353.

49. Lopatina T, Kalinina N, Karagyaur M, Stambolsky D, Rubina K, et al. (2011) Adipose-derived stem cells stimulate regeneration of peripheral nerves: BDNF secreted by these cells promotes nerve healing and axon growth de novo. PLoS One 6: e17899.

50. Lopez MJ, McIntosh KR, Spencer ND, Borneman JN, Horswell R, et al. (2009) Acceleration of spinal fusion using syngeneic and allogeneic adult adipose derived stem cells in a rat model. J Orthop Res 27: 366-373.

51. Ryu HH, Lim JH, Byeon YE, Park JR, Seo MS, et al. (2009) Functional recovery and neural differentiation after transplantation of allogenic adipose-derived stem cells in a canine model of acute spinal cord injury. J Vet Sci 10: 273-284.

52. di Summa PG, Kingham PJ, Raffoul W, Wiberg M, Terenghi G, et al. (2010) Adipose-derived stem cells enhance peripheral nerve regeneration. J Plast Reconstr Aesthet Surg 63: 1544-1552.

53. Lee WP, Yaremchuk MJ, Pan YC, Randolph MA, Tan CM, et al. (1991) Relative antigenicity of components of a vascularized limb allograft. Plast Reconstr Surg 87: $401-411$

54. Kuo YR, Chen CC, Goto S, Huang YT, Wang CT, et al. (2012) Immunomodulatory effects of bone marrow-derived mesenchymal stem cells in a swine hemi-facial allotransplantation model. PLoS One 7: e35459.

55. Kuo YR, Chen CC, Shih HS, Goto S, Huang CW, et al. (2011) Prolongation of composite tissue allotransplant survival by treatment with bone marrow mesenchymal stem cells is correlated with T-cell regulation in a swine hind-limb model. Plast Reconstr Surg 127: 569-579.

56. Lin CS, Lin G, Lue TF (2012) Allogeneic and xenogeneic transplantation of adipose-derived stem cells in immunocompetent recipients without immunosuppressants. Stem Cells Dev 21: 2770-2778.

57. Lindroos B, Suuronen R, Miettinen S (2011) The potential of adipose stem cells in regenerative medicine. Stem Cell Rev 7: 269-291.

58. Fang B, Song Y, Li N, Li J, Han Q, Zhao RC (2009) Mesenchymal stem cells for the treatment of refractory pure red cell aplasia after major ABO-incompatible hematopoietic stem cell transplantation. Ann Hematol 88: 261-266.

59. Fang B, Song Y, Liao L, Zhang Y, Zhao RC (2007) Favorable response to human adipose tissue-derived mesenchymal stem cells in steroid-refractory acute graft-versus-host disease. Transplant Proc 39: 3358-3362.

60. Fang B, Song Y, Lin Q, Zhang Y, Cao Y, et al. (2007) Human adipose tissuederived mesenchymal stromal cells as salvage therapy for treatment of severe refractory acute graft-vs.-host disease in two children. Pediatric transplantation 11: 814-817.

61. Fang B, Song Y, Zhao RC, Han Q, Lin Q (2007) Using human adipose tissue- 
Citation: Khalifian S, Grahammer J, Andrew Lee WP, Brandacher G (2013) Stem Cell-based Tolerance Induction in Transplantation. J Stem Cell Res Ther S6: 003. doi:10.4172/2157-7633.S6-003

derived mesenchymal stem cells as salvage therapy for hepatic graft-versushost disease resembling acute hepatitis. Transplant Proc 39: 1710-1713.

62. Lawitschka A, Ball L, Peters C (2012) Nonpharmacologic treatment of chronic graft-versus-host disease in children and adolescents. Biol Blood Marrow Transplant 18: S74-81.

63. Kuo YR, Goto S, Shih HS, Wang FS, Lin CC, et al. (2009) Mesenchymal stem cells prolong composite tissue allotransplant survival in a swine model. Transplantation 87: 1769-1777.

64. Jones BJ, McTaggart SJ (2008) Immunosuppression by mesenchymal stromal cells: from culture to clinic. Exp Hematol 36: 733-741.

65. Koc ON, Gerson SL, Cooper BW, Dyhouse SM, Haynesworth SE, et al. (2000) Rapid hematopoietic recovery after coinfusion of autologous-blood stem cells and culture-expanded marrow mesenchymal stem cells in advanced breas cancer patients receiving high-dose chemotherapy. J Clin Oncol 18: 307-316.

66. Rieger K, Marinets O, Fietz T, Korper S, Sommer D, et al. (2005) Mesenchymal stem cells remain of host origin even a long time after allogeneic periphera blood stem cell or bone marrow transplantation. Exp Hematol 33: 605-611.

67. Li N, Feugier P, Serrurrier B, Latger-Cannard V, Lesesve JF, et al. (2007) Human mesenchymal stem cells improve ex vivo expansion of adult human CD34+ peripheral blood progenitor cells and decrease their allostimulatory capacity. Exp Hematol 35: 507-515.

68. Majumdar MK, Thiede MA, Haynesworth SE, Bruder SP, Gerson SL (2000) Human marrow-derived mesenchymal stem cells (MSCs) express hematopoietic cytokines and support long-term hematopoiesis when differentiated toward stromal and osteogenic lineages. J Hematother Stem Cell Res 9: 841-848.

69. Leonard DA, Cetrulo CL Jr, McGrouther DA, Sachs DH (2013) Induction of tolerance of vascularized composite allografts. Transplantation 95: 403-409.

70. Li HW, Sykes M (2012) Emerging concepts in haematopoietic cel transplantation. Nat Rev Immunol 12: 403-416.

71. Gornet MF, Randolph MA, Schofield BH, Yaremchuk MJ, Weiland AJ (1991) Immunologic and ultrastructural changes during early rejection of vascularized bone allografts. Plast Reconstr Surg 88: 860-868.

72. Mathe G, Amiel JL, Schwarzenberg L, Cattan A, Schneider M (1963) HAEMATOPOIETIC CHIMERAIN MANAFTER ALLOGENIC (HOMOLOGOUS) BONE-MARROW TRANSPLANTATION. (CONTROL OF THE SECONDARY SYNDROME. SPECIFIC TOLERANCE DUE TO THE CHIMERISM). Br Med J 2: $1633-1635$.

73. Fudaba Y, Spitzer TR, Shaffer J, Kawai T, Fehr T, et al. (2006) Myeloma responses and tolerance following combined kidney and nonmyeloablative marrow transplantation: in vivo and in vitro analyses. Am J Transplant 6: 2121 2133.

74. Spitzer TR, Delmonico F, Tolkoff-Rubin N, McAfee S, Sackstein R, et al. (1999) Combined histocompatibility leukocyte antigen-matched donor bone marrow and renal transplantation for multiple myeloma with end stage renal disease: the induction of allograft tolerance through mixed lymphohematopoietic chimerism. Transplantation 68: 480-484

75. Sharabi Y, Sachs DH (1989) Mixed chimerism and permanent specific transplantation tolerance induced by a nonlethal preparative regimen. J Exp Med 169: 493-502.

76. Tomita Y, Khan A, Sykes M (1994) Role of intrathymic clonal deletion and peripheral anergy in transplantation tolerance induced by bone marrow transplantation in mice conditioned with a nonmyeloablative regimen. J Immunol 153: 1087-1098.

77. Bonilla WV, Geuking MB, Aichele P, Ludewig B, Hengartner H, et al. (2006) Microchimerism maintains deletion of the donor cell-specific CD8+ T cell repertoire. J Clin Invest 116: 156-162.

78. Shirasugi N, Adams AB, Durham MM, Lukacher AE, Xu H, et al. (2002) Prevention of chronic rejection in murine cardiac allografts: a comparison of chimerism- and nonchimerism-inducing costimulation blockade-based tolerance induction regimens. J Immunol 169: 2677-2684.

79. Kawai T, Sachs DH (2013) Tolerance induction: hematopoietic chimerism. Curr Opin Organ Transplant 18: 402-407.

80. Turka LA, Wood K, Bluestone JA (2010) Bringing transplantation tolerance into the clinic: lessons from the ITN and RISET for the Establishment of Tolerance consortia. Curr Opin Organ Transplant 15: 441-448.
81. Ildstad ST, Sachs DH (1984) Reconstitution with syngeneic plus allogeneic or xenogeneic bone marrow leads to specific acceptance of allografts or xenografts. Nature 307: 168-170.

82. Colby C, Chang Q, Fuchimoto Y, Ferrara V, Murphy M, et al. (2000) Cytokinemobilized peripheral blood progenitor cells for allogeneic reconstitution of miniature swine. Transplantation 69: 135-140.

83. Fuchimoto Y, Huang CA, Yamada K, Shimizu A, Kitamura H, et al. (2000) Mixed chimerism and tolerance without whole body irradiation in a large anima model. J Clin Invest 105: 1779-1789.

84. Guzzetta PC, Sundt TM, Suzuki T, Mixon A, Rosengard BR, et al. (1991) Induction of kidney transplantation tolerance across major histocompatibility complex barriers by bone marrow transplantation in miniature swine. Transplantation 51: 862-866.

85. Huang CA, Fuchimoto Y, Scheier-Dolberg R, Murphy MC, Neville DM Jr, et al. (2000) Stable mixed chimerism and tolerance using a nonmyeloablative preparative regimen in a large-animal model. J Clin Invest 105: 173-181.

86. Cosimi AB, Sachs DH (2004) Mixed chimerism and transplantation tolerance. Transplantation 77: 943-946.

87. Kawai T, Cosimi AB, Colvin RB, Powelson J, Eason J, et al. (1995) Mixed allogeneic chimerism and renal allograft tolerance in cynomolgus monkeys Transplantation 59: 256-262.

88. Leventhal J, Abecassis M, Miller J, Gallon L, Ravindra K, et al. (2012) Chimerism and tolerance without GVHD or engraftment syndrome in HLAmismatched combined kidney and hematopoietic stem cell transplantation. Sci Transl Med 4: 124ra128.

89. Kawai $T$, Cosimi AB, Spitzer TR, Tolkoff-Rubin $N$, Suthanthiran $M$, et al. (2008) HLA-mismatched renal transplantation without maintenance immunosuppression. N Engl J Med 358: 353-361.

90. Scandling JD, Busque S, Dejbakhsh-Jones S, Benike C, Millan MT, et al. (2008) Tolerance and chimerism after renal and hematopoietic-cell transplantation. N Engl J Med 358: 362-368.

91. Hongo D, Tang X, Dutt S, Nador RG, Strober S (2012) Interactions between NKT cells and Tregs are required for tolerance to combined bone marrow and organ transplants. Blood 119: 1581-1589.

2. Foster RD, Fan L, Neipp M, Kaufman C, McCalmont T, et al. (1998) Donorspecific tolerance induction in composite tissue allografts. Am J Surg 176: 418421.

93. Prabhune KA, Gorantla VS, Perez-Abadia G, Francois CG, Vossen M, et al (2003) Composite tissue allotransplantation in chimeric hosts part II. A clinically relevant protocol to induce tolerance in a rat model. Transplantation 76: 15481555.

94. Lee WP, Rubin JP, Bourget JL, Cober SR, Randolph MA, et al. (2001) Tolerance to limb tissue allografts between swine matched for major histocompatibility complex antigens. Plast Reconstr Surg 107: 1482-1490; discussion 1491-1482.

95. Bourget JL, Mathes DW, Nielsen GP, Randolph MA, Tanabe YN, et al. (2001) Tolerance to musculoskeletal allografts with transient lymphocyte chimerism in miniature swine. Transplantation 71: 851-856.

96. Mathes DW, Hwang B, Graves SS, Edwards J, Chang J, et al. (2011) Tolerance to vascularized composite allografts in canine mixed hematopoietic chimeras. Transplantation 92: 1301-1308.

97. Hettiaratchy S, Melendy E, Randolph MA, Coburn RC, Neville DM Jr, et al. (2004) Tolerance to composite tissue allografts across a major histocompatibility barrier in miniature swine. Transplantation 77: 514-521.

This article was originally published in a special issue, Transplantation Immunology handled by Editor(s). Qing Ma, University of Texas, USA 